\title{
ENGEVISTA
}

Página da revista: http://www.uff.br/engevista/seer/

\section{Extração de solúveis do mesocarpo de coco verde utilizando solvente e sucessivas extrações}

\section{Extraction of solubles from coconut's mesocarp using solvent and successive extractions}

\author{
Celso Carlino Maria Fornari Junior ${ }^{1}$ \\ Rosilene Aparecida Oliveira ${ }^{2}$ \\ André Mendonça Santos ${ }^{3}$
}

Resumo: A fibra de coco verde é um material abundante, biodegradável e com baixo custo de produção. Apresenta uma alternativa ecologicamente mais adequada para auxiliar na formação de novos materiais compósitos poliméricos com propriedades específicas. Constituída por uma estrutura rígida celulósica denominada holocelulose (celulose e hemicelulose) a fibra é interligada por lignina. Complementando a estrutura, a fibra de coco apresenta uma razoável quantidade de pectina, ceras entre outros constituintes. Quando a lignina e outros solúveis são removidos, a fibra de coco resulta em uma estrutura mais porosa e com menor densidade aparente, podendo ser empregada na formação de materiais mais leves. O emprego da técnica de extração de solúveis denominada lignina de madeira moída foi utilizado para a extração dos solúveis presentes no mesocarpo do coco. O método empregado, consiste na extração de solúveis do mesocarpo micronizado em uma solução de acetona e água sob constante agitação, sendo finalmente separado com auxílio de um meio filtrante. Os resultados indicaram que a cada etapa de extração a quantidade de extrativos diminui, atingindo um total de aproximadamente $50 \%$ em peso de solúveis, após sete etapas de extrações. A densidade aparente do mesocarpo moído antes e após a extração mostrou uma diferença de $55 \%$.

Palavras-chave: fibra de coco; lignina; solvente; cocos nucífera.

\footnotetext{
${ }^{1}$ UESC - Universidade Estadual de Santa Cruz

${ }^{2}$ UESC - Universidade Estadual de Santa Cruz

${ }^{3}$ UESC - Universidade Estadual de Santa Cruz
} 
ISSN: $1415-7314$

ISSN online: 2317-6717

Abstract: The coconut fiber is the natural materials, biodegradable and have a low cost for attainment. Built by the rigid cellulose structure called holocellulose (cellulose and hemicelluloses) the fibers are cover by lignin. Completing the structures the coconut fiber have the significant quantity of the pectin, wax, fact and others. When the lignin and soluble are removed the coconut fiber will results in the more porous structure and low apparent density what can to be used for to build more low density materials. The used of the technique of the extraction of the soluble substances called lignin from the milled wood was used for extraction the soluble from coconut mesocarp. The utilized method is based in the extraction of the soluble from the mesocarp of coconut milled in the solution of the acetone and water under agitation and separated by filtration. The results showed that each extraction step the amount of extractives decreases, taking a total of about $50 \%$ by weight of soluble after seven extractions steps. The apparent density of the milled mesocarp after and before the extraction process showed $55 \%$ of the difference.

Keywords: coconut fiber, lignin, solvent, cocos nucífera. 


\section{Introdução}

A fibra de coco verde (cocos nucífera) é um material natural, abundante e com considerável produção agrícola. Segundos dados do Levantamento Sistemático da Produção Agrícola-IBGE (LSPA), o Brasil produziu 1.989.971 toneladas de coco verde no ano de 2013, com um crescimento positivo de 3,3\% em relação ao ano anterior. Considerando-se que um fruto de coco verde possui peso médio igual a $2.100 \mathrm{~g}$, o mesocarpo do fruto produzirá $105 \mathrm{~g}$ de material seco. Desta forma, o Brasil produziu em 2013 uma quantidade igual a 99.498 toneladas de mesocarpo seco de coco. O aproveitamento e a utilização da fibra de coco verde na produção de novos materiais compósitos, por exemplo, pode contribuir para a demanda crescente de matériaprima, bem como a produção de materiais compatíveis com o meio ambiente (Rout et al., 2001; Ramiers et al., 2011).

As fibras vegetais podem ser utilizadas na confecção de novos materiais com propriedades mais específicas. A diminuição do peso na manufatura dos materiais pode contribuir para a solução de alguns problemas, como diminuição de custo de transporte, principalmente na indústria aeroespacial. A densidade dos materiais, de um modo geral é uma propriedade importante para muitas aplicações (Dam et al., 2006). A redução da densidade nos compósitos, por exemplo, pode favorecer um maior conforto ao usuário, além de possibilitar aplicações com maior desempenho. Na formação de compósitos poliméricos com fibras vegetais, a remoção da lignina da fibra de coco verde pode conduzir a materiais com mais baixa densidade, quando comparado a compósitos feitos com fibra integral (Muensri et al., 2011).

Além disso, a retirada da lignina promoverá transformações físicas, onde o número de irregularidades na superfície pode facilitar a adesão com a matriz polimérica (Bettini et al., 2010). Giannetti et al (2012) tem observado que a presença de lignina sobre a superfície da fibra diminui a ancoragem física com a matriz do compósito, devido a superfície se tornar mais lisa. Outros trabalhos enfatizam que o aumento da rugosidade superficial das fibras vegetais podem trazer ganhos para as propriedades do compósito, devido a uma maior ancoragem mecânica e a maior possibilidade de difusão do polímero para o interior da fibra (Song et al., 2012, Barbosa et al., 2010, Nam et al.,2011). Rahman e Khan (2007) afirmam que o tratamento químico da fibra de coco verde com solução de $\mathrm{NaOH}$ aumenta a rugosidade superficial da fibra, levando a uma melhor interação fibra-matriz. Barbosa et al (2010) observaram que, a presença dos grupos polares da lignina promoveram uma boa interação com a matriz fenólica, devido a sua natureza também polar.

Com relação ao fruto de coco, o seu mesocarpo é constituído por dois tipos distintos de materiais lignino celulósicos, onde a fibra longa e rígida está distribuída em uma matriz macia não fibrosa. A fibra por sua vez é constituída por estruturas de celulose e hemicelulose, denominadas holocelulose as quais são interligadas pela lignina. Ocorre ainda a presença de substâncias como ceras e pectina, que segundo a literatura estão em proporções em torno de 3\% 
em peso. A lignina atua como um agente selante, mantendo coesas e unidas as estruturas rígidas ao mesmo tempo em que protege de agentes externos. A fração de lignina presente na fibra de coco verde segundo a literatura é em torno de 45\% em peso (Saw et al., 2011; Brígida, et al.,2010; Faruk, et al., 2012).

A lignina é um complexo polimérico fenólico e um dos principais componentes da parede celular dos vegetais. É formada pela união covalente de vários monômeros fenólicos com ligações do tipo éter e apresenta resistência a vários agentes hidrolíticos e sistemas enzimáticos (Fukushima e Hatfield, 2003). Constitui-se de uma molécula tri-dimensional amorfa polifenólica, com unidades principais de guaiacila, sirigila e p-hidroxifenila (Muensri et al., 2011; Terashima et al., 1996).

Existem diferentes processos e formas de extração de ligninas, entretanto, alguns métodos não permite obtê-la no estado in natura, pois pode haver interferência entre os procedimentos de extração química e a estrutura da lignina in situ. O método de madeira moída (LMM) é um dos mais utilizados para a obtenção e análise da lignina, devido a lignina sofrer poucas modificações durante o procedimento de extração, além de proporcionar alto rendimento (Morais et al., 1993). Outros métodos como Klason, Organossolve e Hidrólise utilizam temperatura elevada ou reações químicas envolvendo ácidos (Muensri et al., 2011, Morandim et al., 2012). Giannetti et al (2012) extraíram a lignina da fibra do coco verde com tamanhos de $1 \mathrm{~mm}$ utilizando solvente na proporção de 10 partes de solvente para 1 de fibra. A quantidade de lignina obtida foi de aproximadamente $30 \%$.

O estudo se propõe a avaliar quantitativamente a retira de solúveis (lignina e compostos), com sucessivas extrações, de três amostras diferentes do mesocarpo de coco verde, utilizando o método LMM e solução de acetona e água. Desta forma, este trabalho estabelece uma metodologia capaz de controlar a extração seletiva da lignina da fibra do coco. Isso pode permitir que a sua utilização na formação de compósitos alcance propriedades específicas do novo material, como: resistência mecânica, densidade, absorção de umidade, entre outras.

A técnica gravimétrica foi utilizada para quantificar a extração dos solúveis. A medida de densidade aparente do mesocarpo de coco verde moído foi realizada para as amostras antes de submetidas a extração após sete processos extrativos.

\section{Materiais e Métodos}

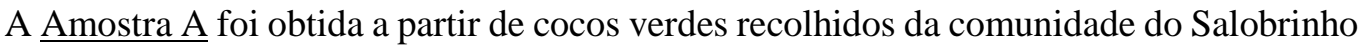
(Ilhéus - BA), sendo provenientes do município de Una-BA. Os frutos sadios foram descascados manualmente e a fração do mesocarpo cortada em partes de aproximadamente 100 x $30 \mathrm{~mm}$ com $10 \mathrm{~mm}$ de espessura. $\mathrm{O}$ mesocarpo foi submetido à secagem em estufa por $24 \mathrm{~h}$ à $110 \pm 5^{\circ} \mathrm{C} \mathrm{e}$ 
após cortado manualmente em tamanhos de aproximadamente 10 x $10 \mathrm{~mm}$ e armazenado em embalagens fechadas. As Amostras B e C foram obtidas pelo processo industrial de desfibrilamento mecânico e separadas com ar forçado. Os frutos de coco verde foram provenientes da região de Una-BA. A amostra B é composta de aproximadamente $95 \%$ em peso da fração macia do mesocarpo e a amostra $\mathrm{C}$ composta de fibras longas de coco (separadas do mesocarpo).

O processo de moagem das amostras foi realizado com o auxilio do moinho de bola da marca Marcone modelo MA, com uma carga total no moinho de $15 \mathrm{~g}$ e 105 esferas. O tempo de moagem foi de 1 hora. Antes do processamento de moagem das amostras, o material foi colocado em aparelho micro-ondas marca Eletrolux modelo ME28S com frequência de $2450 \mathrm{MHz}$, no modo descongelar $(270 \mathrm{~W})$ por um tempo de cinco minutos. O processo foi repetido o número de vezes necessárias até a observação de peso constante.

Para a separação dos tamanhos de partículas, as amostras moídas foram acondicionadas em um jogo de peneiras granulométricas e agitador especifico da marca BERTEL, seguindo os padrões da norma ABNT 10439 método A. Foram selecionadas amostras com tamanho de 150 mesh (abertura de 0,105 mm).

Para a extração dos solúveis, foram realizados três experimentos com quantidades diferentes de amostra A. Foram adicionados 20, 10 ou 5 g de amostra em $200 \mathrm{ml}$ de solução contendo $180 \mathrm{~g}$ de acetona e $20 \mathrm{~g}$ de água. A razão, massa da amostra por massa do solvente foi respectivamente $0,1,0,05$ e 0,025 . O conjunto solução e amostra foram acondicionados em um recipiente de vidro devidamente vedado. O conjunto foi condicionado a um agitador mecânico da marca Servitech modelo CT-054 com velocidade de mistura de $250 \mathrm{rpm}$ por um período de 24 horas a temperatura ambiente. Foram feitas sete extrações consecutivas para a mesma amostra, onde em cada extração foi substituída a solução usada por solução nova. Após cada processo extrativo ocorreu uma diminuição na massa das amostras. Desta maneira, a quantidade de solução foi corrigida de forma a manter a relação original da massa da amostra e solução, isto é, a quantidade de solvente foi calculada para cada nova massa da amostra. Após cada extração, a solução foi filtrada com auxílio de papel filtro. A amostra foi seca por $24 \mathrm{~h}$ a ambiente atmosférico e posteriormente em estufa à $110 \pm 5^{\circ} \mathrm{C}$ por $24 \mathrm{~h}$. As medidas gravimétricas foram realizadas em uma balança marca Bioprecisa modelo FA 2104N com quatro casas decimais. As amostras B e C foram submetidas ao mesmo procedimento de extração da amostra A, entretanto com quantidade de $10 \mathrm{~g}$ de amostra.

A análise por espectrometria no infravermelho utilizou pastilhas de $\mathrm{KBr}$. Os espectros no infravermelho foram registrados no aparelho Spectrum 400.

Microscópio óptico marca Tecnival foi utilizado para registrar imagem do mesocarpo do coco verde. O mesocarpo foi cortado com auxílio de uma faca e seco em estufa a $110 \pm 5^{\circ} \mathrm{C}$ por 24 antes da análise óptica. 
A medida de densidade aparente foi realizada utilizando um recipiente com volume igual a $43 \mathrm{ml}$. A amostra A antes e após de submetida ao processo de extração foi acondicionada e compactada ao recipiente antes da avaliação gravimétrica. A compactação utilizou uma frequência de 180 impactos por minuto durante cinco minutos e utilizou um bastão de vidro. Foi utilizado balança analítica marca Bioprecisa modelo FA 2104N com quatro casas decimais, para as medidas gravimétricas. As medidas de densidade aparente foram feitas com três repetições.

\section{Resultados e Discussão}

O estudo avaliou três tipos de amostras de coco verde. A amostra denominada $\mathbf{A}$, composta do mesocarpo do coco, a amostra $\mathbf{B}$ obtida pelo processamento industrial do fruto e composta por $95 \%$ da fração macia do mesocarpo do fruto e a amostra $\mathbf{C}$ composta por fibras de coco obtidas pelo processamento industrial do fruto, podem ser observadas na Figura 1. As imagens são apresentadas na Figura 1A antes de submetidas ao processo de moagem e na Figura 1B após moagem e com tamanho de partícula de 150 mesh. Observa-se na Figura 1A que, a amostra A apresenta uma coloração mais clara em relação às amostras B e C.

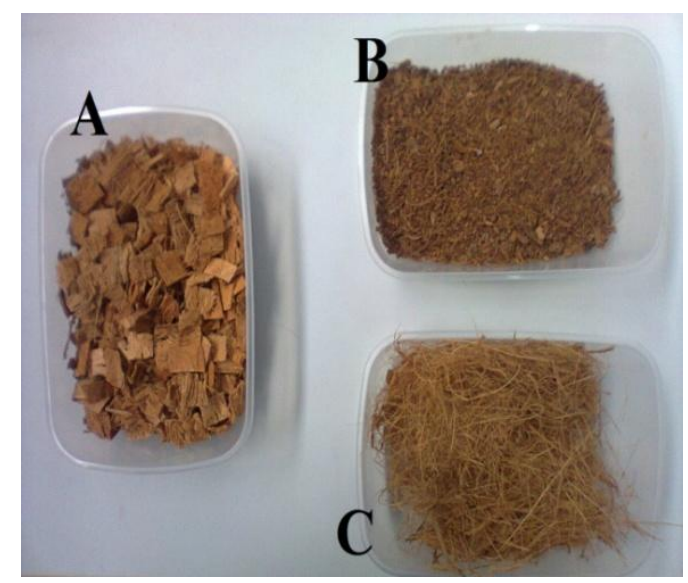

Figura 1A - Amostras antes da moagem. A - mesocarpo, B - fração macia do mesocarpo, $\mathbf{C}$ fibra de coco. 


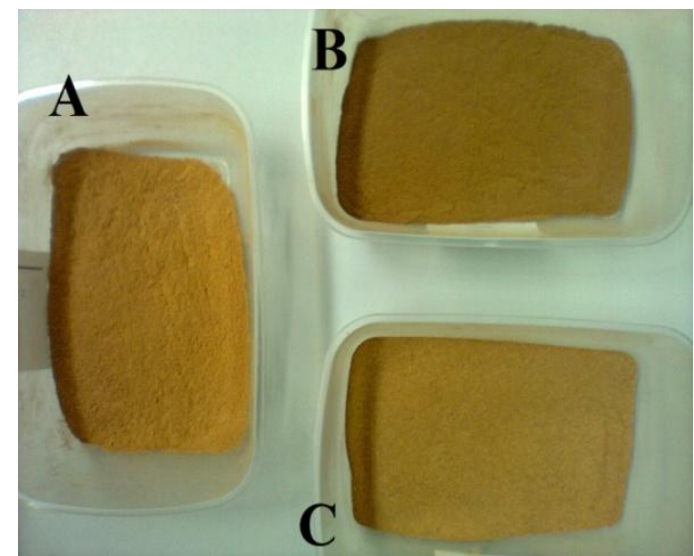

Figura 1B - Fibras, com 150 mesh. A - mesocarpo, B - fração macia do mesocarpo, C - fibra de coco.

A imagem do mesocarpo de coco verde feita em um microscópio óptico, onde a parte macia está interligando as fibras, pode ser observada na Figura 2.

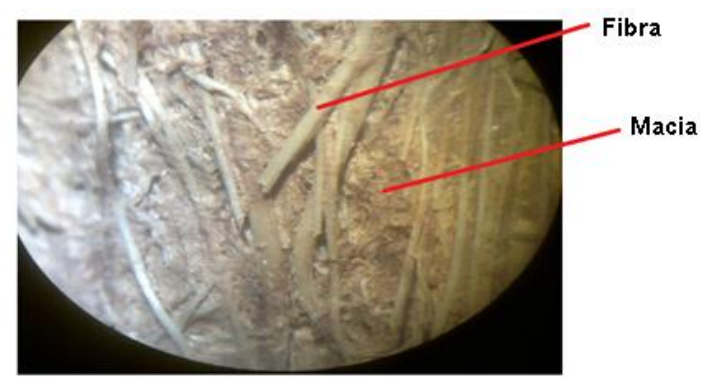

Figura 2 - Mesocarpo do coco verde com 20 vezes de aumento, com destaque para a fração fibra e macia.

A amostra A é composta pelo mesocarpo integral do coco verde, a amostra B é composta pela parte macia e a amostra $\mathrm{C}$ pela fibra.

Os resultados do processo de extração da amostra A revelaram que a cada etapa extrativa, a fração solúvel foi retirada das amostras, resultando na diminuição da massa total das mesmas. Os estudos foram conduzidos de forma que, foram avaliados três diferentes quantidades de amostra para a mesma quantidade de solvente. Foram utilizadas quantidades diferentes de amostras para uma mesma quantidade de solvente, com o fim de avaliar a extração quantitativa da fração solúvel. Conforme dados apresentados na Tabela 1, a extração da fração solúvel foi inversamente proporcional a quantidade de amostra. Isso indica que a maior quantidade de extração de solúveis ocorre quando $5 \mathrm{~g}$ da amostra está presente em uma quantidade igual de 200 $\mathrm{ml}$ de solução, comparando-se aos valores avaliados neste estudo.

A medida que o processo de extração aumentava em número, a solução alterou de uma cor castanho escuro na primeira extração até uma tênue cor bege clara na sétima etapa de extração, 
indicando que a concentração dos extrativos diminuiu com aumento do número de extrações. Os resultados gravimétricos demonstraram que a cada etapa de extração a quantidade de extrativos diminui. Para o caso da amostra com 5 g (razão 0,025), a primeira extração retirou 11,49\% de solúveis e a sétima $4,10 \%$. Isso indica uma queda na retirada dos solúveis pela ação da solução, na medida em que a extração se processa. Segundo Rodrigues e Pinto (2007) a extração da lignina é dependente do tempo de contato entre a amostra e a solução extrativa. Para a diminuição do rendimento extrativo ao longo da sequência dos processos, duas causas principais podem ser atribuídas. A concentração de solúveis nas partículas de fibra de coco diminui em cada etapa. Além disso, os solúveis localizados nas regiões mais externas das partículas interagem prioritariamente com a solução, devido ao contato físico ser mais favorecido.

A Tabela 1 apresenta a percentagem de solúveis extraídos para cada processo de extração e quantidade de amostra A.

Tabela 1. Percentagens de solúveis e massas de amostra A antes e após cada etapa de extração. Razão de extração 0,1, 0,05 e 0,0025.

\begin{tabular}{|c|c|c|c|}
\hline Extração & $\begin{array}{l}\text { Fibra antes da extração } \\
\text { (g) }\end{array}$ & $\begin{array}{l}\text { Fibra após a extração } \\
\text { (g) }\end{array}$ & $\begin{array}{l}\text { Solúveis extraídos } \\
(\%)\end{array}$ \\
\hline $1^{\mathrm{a}}$ & $\begin{array}{r}20,0700 \\
10,0080 \\
5,050\end{array}$ & $\begin{array}{l}18,4231 \\
9,0360 \\
4,4301\end{array}$ & $\begin{array}{l}8,20 \\
9,72 \\
11,49\end{array}$ \\
\hline $2^{a}$ & $\begin{array}{r}16,0210 \\
8,834 \\
3,9179\end{array}$ & $\begin{array}{c}15,1552 \\
8,2448 \\
3,4854\end{array}$ & $\begin{array}{c}5,40 \\
6,66 \\
11,04\end{array}$ \\
\hline $3^{a}$ & $\begin{array}{r}12,0920 \\
6,0771 \\
3,0319\end{array}$ & $\begin{array}{c}11,5672 \\
5,7390 \\
2,7980\end{array}$ & $\begin{array}{l}4,34 \\
5,56 \\
7,71\end{array}$ \\
\hline $4^{a}$ & $\begin{array}{r}8,0512 \\
4,0399 \\
2,0551\end{array}$ & $\begin{array}{l}7,7890 \\
3,8659 \\
2,7980\end{array}$ & $\begin{array}{l}3,25 \\
4,30 \\
6,53\end{array}$ \\
\hline $5^{a}$ & $\begin{array}{l}6,0602 \\
3,0310 \\
1,5290\end{array}$ & $\begin{array}{l}5,8500 \\
2,9077 \\
1,4400\end{array}$ & $\begin{array}{l}3,46 \\
4,06 \\
5,49\end{array}$ \\
\hline
\end{tabular}




\begin{tabular}{|c|c|c|c|}
\hline $6^{\mathrm{a}}$ & 4,8023 & 4,6525 & 3,11 \\
& 2,4149 & 2,3217 & 3,85 \\
& 1,2046 & 1,1528 & 4,31 \\
\hline $7^{\mathrm{a}}$ & 4,0091 & 3,8888 & 3,00 \\
& 2,0242 & 1,9520 & 3,56 \\
& 0,9462 & 0,9071 & 4,10 \\
\hline Total & & & 30,76 \\
& & & 37,71 \\
& & & 50,67 \\
\hline
\end{tabular}

.Para cada etapa subsequente de extração, ocorreu uma diminuição no peso da amostra. Isto está relacionado com a retirada da amostra do papel de filtro após a etapa de filtração e secagem. Observa-se que a percentagem de solúveis extraídos diminui a cada novo processo de extração.

Dados da literatura mostram diferentes teores de lignina extraída para diferentes tipos de processos extrativos. Para a fibra de coco verde tratada por 90 minutos com solução 0,7 de $\mathrm{NaClO}_{2}$ à quente, foram registrados a extração de $21 \%$ da lignina presente na fibra de coco, a qual é constituída por um total de $42 \%$ em peso de lignina (Muensri et al., 2011). A literatura relata que diferentes métodos de extração da lignina podem conduzir para diferentes rendimentos extrativos de lignina das amostras, onde um dos processos com maior rendimento é o LMM (Saliba et al., 2001). O método que utilizou xilenosulfonato de sódio em solução aquosa obteve rendimento variável de lignina em função do tipo de amostra de fibra utilizada (Korpinen \& Fardim, 2009).

A comparação do total da fração mássica de solúveis após sete etapas de extrações para cada razão amostra/solvente pode ser observado na Figura 3. Na razão igual à 0,025 , o total extraído atingiu 50,67\% da massa inicial do mesocarpo de coco verde. A fração solúvel contida na fibra do coco é segundo Nam et al (2011) no máximo 45\%. Segundo Saw et al (2011), o conteúdo da lignina encontrado na fibra de coco foi igual a 46,8\%. Os trabalhos de Brígida et al (2010) registraram quantidade máxima de $46,01 \%$ de lignina na fibra de coco natural. Para os processos extrativos que usaram razão igual á 0,05 e 0,1 , a percentagem de solúveis foi inferior ao valor teórico atribuído na literatura. 


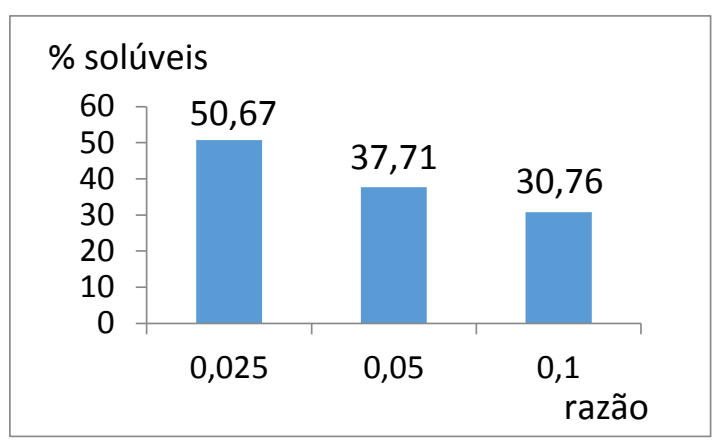

Figura 3 - Total de solúveis extrativos de amostra de mesocarpo do coco verde após sete processos consecutivos.

Considerando que para a razão de 0,025 a extração foi máxima, com o aumento da razão de 0,025 para 0,05 a extração de solúveis foi aproximadamente $25 \%$ inferior, e com a razão 0,1 foi aproximadamente $40 \%$ inferior.

Foi investigada a extração de solúveis das amostras B e C, isto é, fração macia e fibra separadamente. Para estes tipos de amostras foi estabelecida a razão de 0,05 , a qual é um valor intermediário das massas analisadas com a amostra A. A Tabela 2 apresenta os resultados em proporção mássica da extração de solúveis.

Os resultados revelam que a amostra B apresentou em todas as etapas de extração, uma quantidade superior a amostra C. Ao final do processo, foi registrado uma extração total igual a $32,12 \%$ de solúveis para a amostra B e 21,87\% para a amostra C. A diferença corresponde a aproximadamente $10 \%$ e indicam a maior facilidade de extração para a parte macia do mesocarpo do coco verde em comparação com a sua fibra.

Os resultados percentuais para cada processo de extração, para as amostras B e C, são apresentados na Figura 4. O gráfico permite analisar comparativamente a quantidade de extrativos para os dois tipos de amostras e em função do número de extrações.

Tabela 2 - Massa extraída e das amostras B e C em função das etapas extrativas.

\begin{tabular}{|c|c|c|c|c|c|c|c|c|c|}
\hline & Extração & $\mathbf{1}^{\mathbf{a}}$ & $\mathbf{2}^{\mathbf{a}}$ & $\mathbf{3}^{\mathbf{a}}$ & $\mathbf{4}^{\mathbf{a}}$ & $\mathbf{5}^{\mathbf{a}}$ & $\mathbf{6}^{\mathbf{a}}$ & $\mathbf{7}^{\mathbf{a}}$ & Total \\
\hline $\mathrm{A}$ & Amostra & 10,1020 & 8,0073 & 6,0016 & 4,0054 & 3,0015 & 2,4001 & 2,0010 & \\
$\mathbf{M}$ & antes da & & & & & & & & \\
$\mathrm{O}$ & extração(g) & & & & & & & & \\
$\mathrm{S}$ & Amostra & 9,2074 & 7,8405 & 5,7626 & 3,8680 & 2,9008 & 2,3267 & 1,9431 & \\
$\mathrm{~T}$ & após da & & & & & & & & \\
$\mathrm{R}$ & extração(g) & & & & & & & & \\
\hline
\end{tabular}




\begin{tabular}{|c|c|c|c|c|c|c|c|c|c|}
\hline $\begin{array}{c}\text { A } \\
\text { B } \\
\text { (macia) }\end{array}$ & $\begin{array}{c}\text { Massa } \\
\text { extraída(\%) }\end{array}$ & 8,85 & 6,57 & 3,98 & 3,43 & 3,35 & 3,05 & 2,89 & 32,12 \\
\hline $\begin{array}{l}\mathrm{A} \\
\mathrm{M} \\
\mathrm{O}\end{array}$ & $\begin{array}{c}\text { Amostra } \\
\text { antes da } \\
\text { extração(g) }\end{array}$ & 10,0157 & 8,0167 & 6,0270 & 4,0481 & 3,0432 & 2,4026 & 2,0083 & \\
\hline $\begin{array}{l}\mathrm{S} \\
\mathrm{T} \\
\mathrm{R}\end{array}$ & $\begin{array}{l}\text { Amostra } \\
\text { após da } \\
\text { extração(g) }\end{array}$ & 9,4867 & 7,6470 & 5,8449 & 3,9462 & 2,9727 & 2,3520 & 1,967 & \\
\hline $\begin{array}{c}\text { A } \\
\text { C } \\
\text { (fibra) }\end{array}$ & $\begin{array}{c}\text { Massa } \\
\text { extraída }(\%)\end{array}$ & 5,28 & 4,61 & 3,02 & 2,51 & 2,31 & 2,10 & 2,04 & 21,87 \\
\hline
\end{tabular}

Para ambas as amostras e a partir da terceira extração, o gráfico mostra uma diminuição na inclinação da reta, indicando que a quantidade mássica de solúveis extraídos diminuiu.

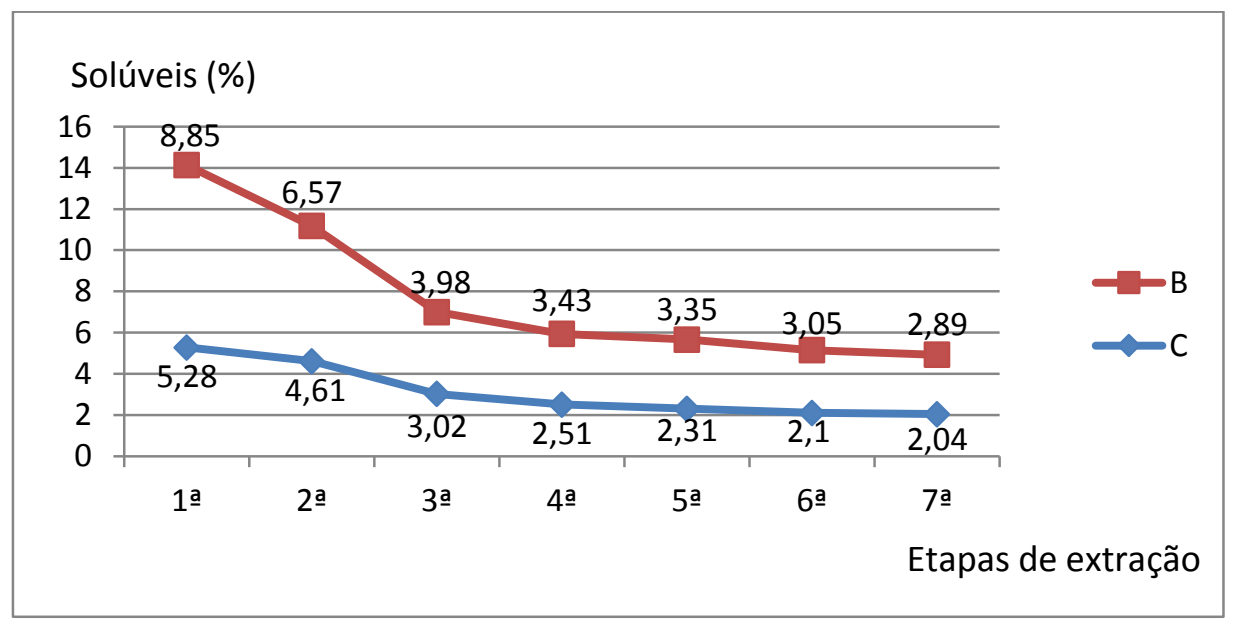

Figura 4 - Percentagem de solúveis extraídos em função do número de extrações, para amostras B e C.

Comparando-se as amostras B e C com a amostra A, diferença significativa é o percentual de solúveis extraídos. A amostra A apresentou uma quantidade igual a 37,71\% e as amostras B e C 32,12 e 21,87\% respectivamente. Muito provavelmente, a fibra obtida pelo processo industrial sofreu modificações devido a sua exposição ao ambiente atmosférico, o que pode ter resultado em uma oxidação parcial da lignina (Barbosa et al., 2010; Leblanc et al., 2006).

Os resultados de densidade aparente realizados para a amostra $\mathrm{A}$, foram feitos antes $\mathrm{e}$ após o processo de extração de solúveis. Os resultados são apresentados na Tabela 3 , onde a 
amostra A após sete extrações apresenta um valor de $0,272 \mathrm{~g} / \mathrm{cm}^{3}$. Este valor é $55 \%$ inferior a amostra que não foi submetida ao processo de extração. A diferença entre as amostras consiste na maior porosidade da amostra submetida ao processo de extração, pela retirada de solúveis, o que na sua grande maioria é composto por lignina. A retirada dos solúveis diminui a massa das amostras ao mesmo tempo em que a estrutura celulósica (holocelulose) mantêm o seu volume muito próximo ou igual ao original.

Tabela 3 - Densidade aparente da amostra A (mesocarpo) antes e após a extração

\begin{tabular}{|c|c|}
\hline \multicolumn{2}{|c|}{ Amostra A (mesocarpo do coco verde -150 mesh) } \\
\hline Antes do processo de extração & Após sete extrações \\
\hline $\mathbf{0 , 4 9 5} \mathrm{g} / \mathrm{cm}^{3}$ & $\mathbf{0 , 2 7 2} \mathrm{g} / \mathrm{cm}^{3}$ \\
\hline
\end{tabular}

Espectro infravermelho é uma técnica utilizada para caracterização e análise qualitativa de fibras vegetais. Segundo Sócrates (1994) o espectro infravermelho de qualquer substancia é interpretado e utilizado para conhecer as frequências relativas a determinado tipo de grupo ou ligação química. A aplicação da transformada de Fourier para analise instrumental de espectroscopia de infravermelho tem possibilitado estudos analíticos de vegetais sólidos e seus respectivos componentes (Owen e Thomas, 1989).

O espectro de absorção infravermelho da amostra A, antes de submetida ao processo de extração (A) e após sete etapas de extração (B), estão expostos na Figura 5-A e 5-B.

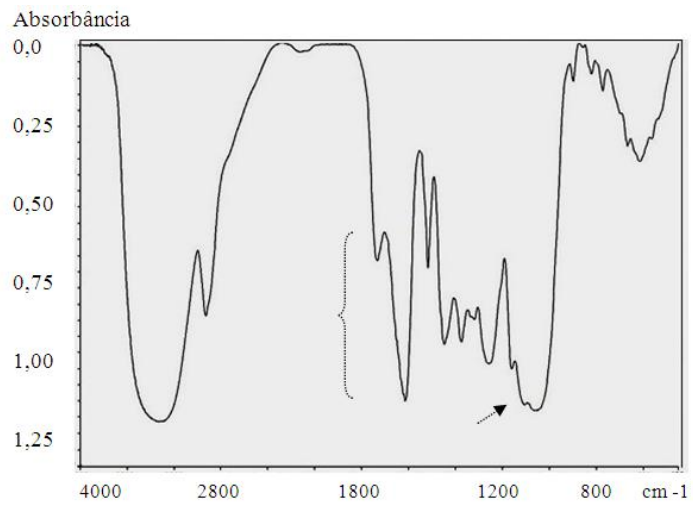

Figura 5-A - Espectro no infravermelho da região entre 4000 a $600 \mathrm{~cm}^{-1}$ do mesocarpo do coco verde (amostra A) antes da extração. 


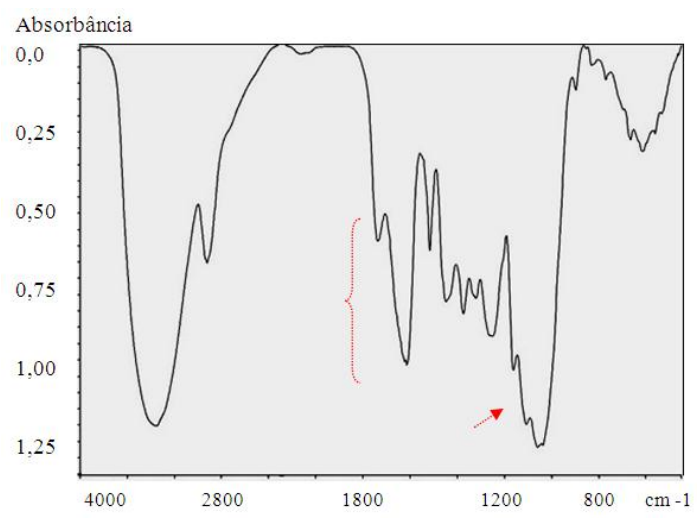

Figura 5-B - Espectro no infravermelho da região entre 4000 a $600 \mathrm{~cm}^{-1}$ do mesocarpo do coco verde (amostra A) após sete extrações.

Observa-se que ocorreram algumas variações com os espectros da amostra A antes de submetida ao processo de extração, conforme observa-se na Figura 5-A e após sete etapas de extração, conforme Figura 5-B. Para a amostra submetida ao processo de extração observa-se que o pico próximo a região $1600 \mathrm{~cm}^{-1}$ indicado pelo colchete apresenta uma forma menos alongada, o pico próximo a $1100 \mathrm{~cm}^{-1}$ indicado pela seta apresenta uma deformação mais afinada e longa e o pico em torno de $3300 \mathrm{~cm}^{-1}$ mostrou-se mais afinado.

As ampliações da região no infravermelho com os picos de absorção entre as regiões de $4000 \mathrm{~cm}^{-1}$ a $2800 \mathrm{~cm}^{-1}$, são apresentadas na Figura 6-A e 6-B.

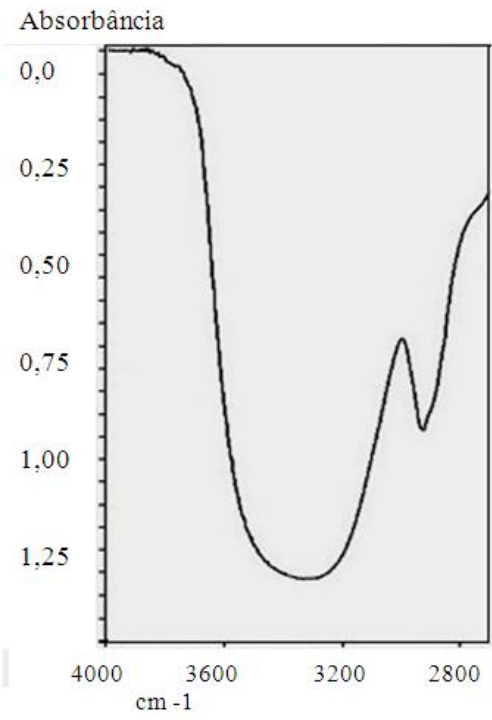

Figura 6-A - Espectro ampliado entre 4000 e $2800 \mathrm{~cm}^{-1}$ da amostra A antes da extração. 


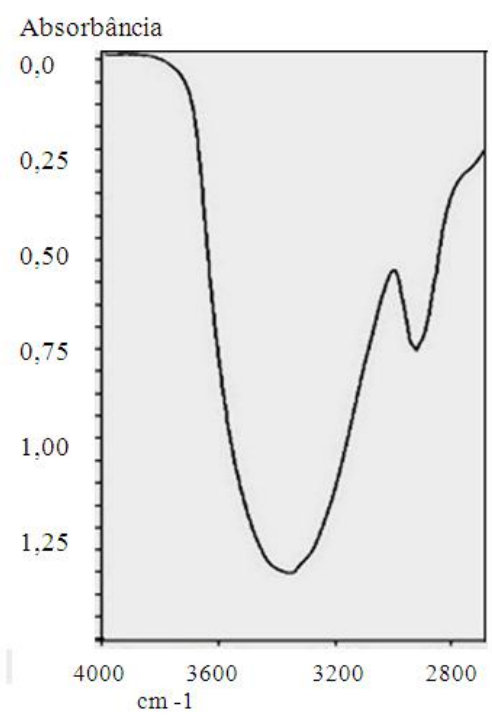

Figura 6-B - Espectro ampliado entre 4000 e $2800 \mathrm{~cm}^{-1}$ da amostra A após sete extrações.

Segundo Satyanarayana (2007) a região próxima de $3300 \mathrm{~cm}^{-1}$ e segundo Guimarães (2009) a região em torno de $3400 \mathrm{~cm}^{-1}$ é referente a vibrações do grupo hidroxila $(\mathrm{OH})$. A pesquisa de OWEN e THOMAS (1989), que envolveu os estudos em infravermelho da madeira dura e macia, a larga e forte banda em torno de $3400 \mathrm{~cm}^{-1}$ é atribuída ao grupamento $\mathrm{OH}$. O estreitamento da banda na região de $3400 \mathrm{~cm}^{-1}$ para a amostra que sofreu extração indica que, ocorreram mudanças relacionadas com o grupamento $\mathrm{OH}$. Isto pode indicar a alteração na amostra devido a retirada de solúveis, onde na sua maior parte é composta de lignina, a qual possui acentuada presença de grupos $\mathrm{OH}$.

As ampliações nas regiões entre $1800 \mathrm{~cm}^{-1}$ á $1200 \mathrm{~cm}^{-1}$, são apresentados na Figura 7-A e 7-B. O pico importante desses espectros envolve a região de 1600 e $1510 \mathrm{~cm}^{-1}$, onde OWEN e THOMAS (1989) relata que essas absorções estão associadas à deformação de anéis aromáticos. Segundo Guimarães (2009), a região próxima a $1650 \mathrm{~cm}^{-1}$ pode ser atribuída ao carbono conjugado presente em grupos típicos de lignina. 


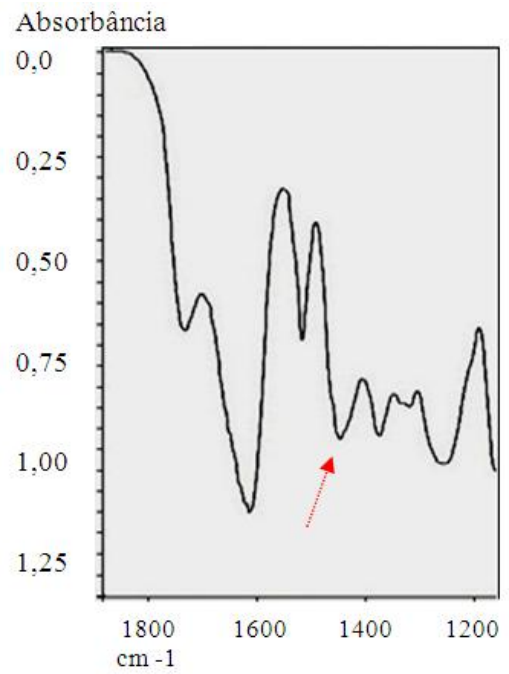

Figura 7-A - Espectro ampliado entre 1800 e $1200 \mathrm{~cm}^{-1}$ da amostra A antes da extração.

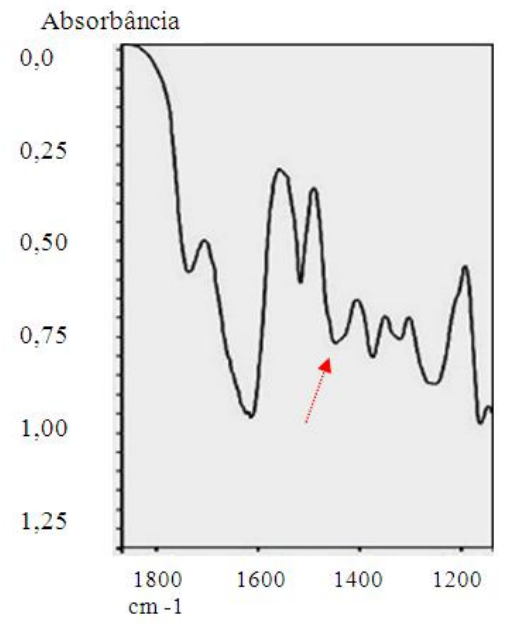

Figura 7 B - Espectro ampliado entre 1800 e $1200 \mathrm{~cm}^{-1}$ da amostra A após sete extrações.

Segundo Saliba (2009) os picos 1424, 1512 e $1606 \mathrm{~cm}^{-1}$ são atribuídos ao grupo C=O conjugado característico da lignina. Observa-se que a amostra que sofreu extração mostra uma diminuição no pico correspondente a $1424 \mathrm{~cm}^{-1}$ o que pode indicar a redução da lignina na amostra.

\section{Conclusão}

1. A eficiência do método da Lignina de Madeira Moída (LMM) para extrair lignina da fibra de coco verde foi analisada em sete etapas consecutivas de extração. A analise dos resultados revela que a eficiência de extração da lignina depende da quantidade de fibra de coco verde 
presente na solução. Para a relação amostra/solvente igual a 0,025 , obteve-se a maior quantidade de extração, correspondendo á 50,67\% em peso, após sete extrações.

2. O processo de extração utilizado neste trabalho para as amostras obtidas industrialmente, revelou que a extração de solúveis foi diferente para a amostra constituída fração fibra e a amostra constituída pela fração macia. Os espectros nas analises no infravermelho indicaram caracterizar as vibrações das ligações químicas de compostos específicos e que segundo a literatura, constituem a estrutura geral característica da lignina.

3. Foi possível extrair a temperatura ambiente, a fração solúvel das amostras de fibra de coco utilizando- acetona e água. A quantidade percentual de extração é dependente do tipo de fibra de coco verde.

4. A densidade aparente do mesocarpo de coco verde da amostra A com 150 mesh, apresentou densidade igual a $0,495 \mathrm{~g} / \mathrm{cm}^{3}$ e após sete etapas de extração de solúveis diminuiu para $0,272 \mathrm{~g} / \mathrm{cm}^{3}$.

5. A análise por espectroscopia de infravermelho revelou que, houve modificações em relação a alguns picos característicos das fibras lignino celulósicas. 


\section{Agradecimentos}

Á FAPESB e UESC, pelo apoio à pesquisa.

\section{Referências}

BARBOSA, V.J., RAMIRES, E.C., RAZERA, I.A.T., FROLLINI, E. 2010. Biobased composites from tannin-phenolic polymers reinforced with coir fibers. Industrial Crops and Products, 32, 305-312.

BETTINI, S.H.P., BICUDO, A.B.L.C., AUGUSTO, I.S., ANTUNES, L.A., MORASSI, P.L. CONDOTTA, R., BONSE, B.C. 2010. Investigation on the of coir fiber as alternativa reinforcement in polypropylene. Journal of Applied Polymer Science, 118, 2841-2848 BRÍGIDA, A.I.S., CALADO, V.M.A., GONÇALVES, L.R.B., COELHO, M.A.Z. 2010. Effect of chemical treatment on properties of green coconut fiber. Carbohydrate Polymers, 79, 832-838.

DAM, E.G. J., OEVER, M.J.A., KEIJSERS, E.R.P., PUTTEN, J.C., ANAYRON, C., JOSOL, F., PERALTA A., 2006. Process for production of high density/high performance binderless boards from whole coconut husk. Part 2: Coconut husk morphology, composition and properties. Industrial Crops and Products, 24, 96-104.

FARUK,O., BLEDZKI, A.K., FINK, H.P., SAIN, M. 2012. Biocomposites reinforced with natural fibers: 2000-2010. Progress in Polymers Science, 37, 1552-1596.

FUKUSHIMA, R.S., HATFIELD, R.D. Um novo método analítico para a determinação do teor de lignina em produtos vegetais. In: VIII Encontro Nacional Sobre Métodos dos Laboratórios da Embrapa, Jaguariúna, 2003, São Paulo, Brasil.

GIANNETTI, A.A.M., AGNELli, J.A.M., LANÇAS, B., MAGNABOSCO, R., CASARIN, S.A., BETTINI, S.H.P. 2012. Lignin as additive in polypropylene/coir composites: Thermal, mechanical and morphological properties, Carbohydrate Polymers, 87, 2563-2568.

GUIMARÃES, J.L., FROLLINI, E., SILVA, C.G., WYPYCH, F., SATYANARAYANA, K.G. 2009. Characterization of banana, sugarcane bagasse and sponge gourd fibers of Brazil. Industrial Crops And Products, 30, 407-415.

LSPA/2012 - LEVANTAMENTO SISTEMÁTICO DA PRODUÇÃO AGRÍCOLA IBGE. ftp://ftp.ibge.gov.br/Producao_Agricola/...da.../2012/spa_201202.pdf

KORPINEN R., FARDIM P. 2009. Extração de lignina de biomassa de madeira mediante uma solução hidrotrópica. O Papel, 69-82.

LEBlANC J.L., FURTADO, C.R.G., LEITE, M. C. A. M., VISCONTE, L. L. Y., 
ISHISAKI, M. H. 2006. Investigating polypropylene-green coconut fiber composites in the molten and and solid states through various techniques. Applied Polymer Science, 102, 1922-1936.

MORAIS, S.A.L., PILÓ-VELOSO, D. NASCIMENTO, E.A. 1993. Isolamento e análise estrutural de ligninas. Química Nova, 16, (5), 435-948.

MORANDIM G.A.A., AGNELLI, J.A.M., LANÇAS, B.Z., MAGNABOSCO, R., CASARIN, S.A., BETTINI, S.H.P. 2012. Lignin as additive in polypropylene/coir composites: thermal, mechanical and morphological properties. Carbohydrate Polymers, 87, 2563-2568.

MUENSRI, P., KUNANOPPARAT, T., MENUT, P., SIRIWATTANAYOTIN, S. 2011. Effect of lignin removal on the properties of coconut coir fiber/wheat glúten biocomposite. Composites: Part A, 42, 173-179.

NAM, T.H., OGIHARA, S., TUNG, N.H., KOBAYASHI, S. 2011. Effect of treatment on interfacial and mechanical properties of coir fiber reinforced poly(butylenes succinate) biodegradable composites. Composites: Part B, 42, 1648-1656.

OWEN N.L., THOMAS D.W. 1989. Infrared studies of "hard" and "soft" Woods. Applied Spectroscopy, 43, 451-455.

RAHMAN M.M., KHAN M.A. 2007. Surface treatment of coir (Cocosnucifera) fibers and its influence on the fibers physico-mechanical properties. Composites Science \& Technology, 2007 67, 2369-2376.

RAMIERS, M.G.L., SATYANARAYANA, K.G., IWAKIRI, S., MUNIZ, G.B., TANOBE, V., SAHAGUN, T.S.F. 2011. Study of the properties of biocomposites. Part I. Cassava starch-green coir fibers from Brazi. Carbohydrate Polymers , 86, 1712-1722. RODRIGUES S., PINTO G.A.S. 2007. Ultrasound extraction of phenolic compouds from coconut (cocos nucifera) shell powder. Journal of Food Engineering, 80, 869-872.

ROUT, J., MISRA, M., TRIPATHY, S.S., NAYAK, S.K., MOHANTY, A.K. 2001. The influence of fibre treatment on the performance of coir-polyester composites. Composite Science and Technology, 61, 1303-1310.

SALIBA, E.O.S., RODRIGUEZ, N.M., MORAIS, S.A.L.; PILÓ-VELOSO, D. 2001. Lignina - Métodos de obtenção e caracterização química. Ciência Rural, 69-82.

SATYANARAYANA, K.G., GUIMARÃES, J.L., WYPYCH, F. 2007. Studies on lignocellulosic fibers of brazil.part i: source, production, morphology, properties and applications. Composites Part A: Applied Science and Manufacturing, 38, 1694-1709. SAW, S.K., SARKHEL, G., CHOUDHURY, A. 2011. Surface modification of coir fibre 
involving oxidation of lignins followed by reaction with furfurayl alcohol: Characterization and stability. Appliesd Surface Science, 257, 3763-3769.

SÓCRATES, G. Infrared characteristic group frequencies, 2 ed., Chichester, Wiley. 1994.

SONG, B., MENG, L.H., HUANG, Y.D. 2012. Influence of plasma treatment time on plasma induced vapor phase grafting modification of PBO fiber surface. Applied Surface Science, 258, 5505-5510.

TERASHIMA, N., ATALLA, R.H., RALPH, S.A., LANDUCCI, L.L., LITPIERRE, C., MONTIES, B 1996. New preparation of lignin polymer models under conditions that approximate cell wall lignifications. Holzforschung, 50, 9-14. 